\title{
URBAN FRINGE BELTS EM CIDADES NOVAS: O CASO DE MARINGÁ - BRASIL
}

\author{
URBAN FRINGE BELTS IN PLANNED NEW TOWNS: \\ THE CASE OF MARINGÁ - BRAZIL
}

\section{Juliana Alves Pereira}

Mestre em Engenharia Urbana pela Universidade Estadual de Maringá

arq.jul@hotmail.com

\section{Karin Schwabe Meneguetti}

Doutora e professora adjunta do Departamento de Arquitetura e Urbanismo da Universidade Estadual de Maringá

ksmeneguetti@uem.br.

\section{Renato Leão Rego}

Doutor e professor associado do Departamento de Arquitetura e Urbanismo da Universidade Estadual de Maringá

rlrego@vem.br.

\section{RESUMO}

Este trabalho trata de averiguar a existência e características das urban fringe belts em uma cidade nova planejada: Maringá, Paraná. M. R. G. Conzen depurou o conceito das urban fringe belts, concebido por Hebert Lovis pela observação do crescimento de cidades medievais. De acordo com Conzen, urban fringe belts configuram fisicamente o desenvolvimento urbano e podem ser vislumbradas pela concentração de serviços públicos e institucionais na borda da malha urbana, em decorrência de áreas residenciais de expansão; desse modo, as fringe belts representam, em anéis concêntricos, ciclos econômicos da vida urbana e ondas de crescimento da mancha da cidade. No entanto, a possível existência das urban fringe belts em uma cidade nova planejada sugere um caso um pouco diferente. Assim, um método de análise particular foi adaptado à realidade de Maringá. Equipamentos públicos e lotes particulares de baixa ocupação foram considerados. As urban fringe belts foram sinalizadas em mapas subsequentes de desenvolvimento urbano, o que permitiu a representação do início, estagnação e modificação das urban fringe belts em cinco períodos de crescimento urbano. Como resultado foi observado que, apesar das peculiaridades de uma cidade nova, é possível identificar urban fringe belts. Em Maringá ainda notamos duas formações distintas: urban fringe belts mais consistentes, formadas pelo zoneamento urbano, e urban fringe belts de uso institucional, que surgem acompanhando o crescimento urbano.

Palavras-chave: Espaços livres, evolução urbana, morfologia urbana, cidades novas, urban fringe belts.

\footnotetext{
ABSTRACT

This paper aims to ascertain the existence and characteristics of urban fringe belts in a planned new town. M. R. G. Conzen debugged the concept of urban fringe belts, designed by Hebert Louis by the observation of medieval cities. According to Conzen, urban fringe belts shape physically and urban development can be glimpsed through the merger of public and institutional reforms of the urban edge, due to expansion of residential areas, thereby representing the fringe belts in concentric rings, cycles of life and urban growth
} 
waves spot in town. However, the possible existence of urban fringe belts in a planned new town suggests a slightly different case. Thus, a particular analysis method was adapted to the reality of Maringa, Brazil. Public facilities and private lots of low occupancy were considered. The urban fringes were then signaled on subsequent maps of urban development which allowed representing the emergence, stagnation and modifying of urban fringe belts in five periods of urban growth. As a results showed that, despite the peculiarities of a new city, is possible to identify urban fringe belts. In Maringá it's also noticed two distinct formations: urban fringe belts more consistent, formed by zoning and; urban fringe belts of institutional use that arise accompanying urban growth.

Keywords: Open spaces, urban evolution, urban morphology, new towns, urban fringe belts.

\section{INTRODUÇÃO}

As cidades são como organismos vivos, em contínua transformação por seus habitantes e seus atores sociais. Não só seu traçado original e suas peculiaridades são objetos de estudo da morfologia urbana: sua evolução urbana é também um grande tema de interesse dessa área do conhecimento. Mais precisamente, um aspecto bastante interessante da evolução da forma urbana é o caso das urban fringe belts'.

Inicialmente, as urban fringe belts distinguiam grandes áreas de baixa ocupação e uso não residencial que, no decorrer do tempo, estabeleciam-se na periferia da malha urbana da cidade após fortes períodos de expansão (CONZEN, 2008). A terminologia surgiu relacionada às áreas contíguas aos muros que cercavam as cidades medievais. Em 1960, o geógrafo alemão M. R. G. Conzen introduziu esse conceito em estudos de morfologia urbana, caracterizando as urban fringe belts como hiatos do crescimento urbano estabelecidos em período de lento desenvolvimento.

O seu conhecimento possibilita a intervenção para melhorias urbanas a fim de integrar esses espaços à malha consolidada da cidade. As urban fringe belts podem até mesmo colaborar para a criação de uma rede de espaços livres na cidade, além de contribuir para a melhoria da qualidade de vida de seus habitantes (KRISTJANSDOTTIR, 2008).

A análise das urban fringe belts já vem sendo realizada em diversas partes do mundo como parte de estudos morfológicos. M. P. Conzen (2008) estudou centros urbanos fora da Europa, onde aparecem as urban fringe belts. No Brasil, os estudos liderados por Stael de Alvarenga Pereira Costa localizaram aquelas em Belo Horizonte - Minas Gerais (PEREIRA COSTA et al, 2009). Ainda assim, pouco existe a esse respeito no caso de cidades novas. Cidades que não foram implantadas na Idade Média e, portanto, não possuíam, em sua malha urbana, a muralha, elemento relacionado à formação das urban fringe belts. Todavia, sabe-se que os distintos usos do solo e ocupações institucionais, de lazer e até mesmo industriais, podem compor os cinturões das urban fringe belts, mesmo nas cidades projetadas, planejadas e implantadas na íntegra como novo assentamento, segundo características específicas da região. Nesse sentido, esta pesquisa pretende averiguar a existência das urban fringe belts em cidades novas planejadas, partindo do estudo de caso da cidade de Maringá.

Para o amplo desenvolvimento deste trabalho, fez-se uma breve abordagem do conceito, aplicações e a metodologia de estudo para a localização e análise das urban 
fringe belts no contexto local. Posteriormente, fez-se a apresentação da cidade objeto deste estudo e a aplicação do conceito em sua realidade, levando-se em conta seu histórico, seus ciclos econômicos e ainda a gênese e evolução das urban fringe belts. E, por fim, discorreu-se sobre as conclusões finais.

\section{URBAN FRINGE BELTS}

A morfologia urbana é de fundamental importância para se compreender as cidades, as peculiaridades de seu traçado e sua evolução urbana. As urban fringe belts fazem parte de um conceito morfológico mais elaborado que se refere às áreas de expansão urbana ou áreas de acréscimos diferenciados nos tecidos urbanos consolidados (REGO; MENEGUETTI, 2011).

Contribuindo sensivelmente para o estudo e observação das formas urbanas, Herbert Louis, em 1936, fez a primeira conceituação que distinguia grandes áreas de baixa ocupação e uso não residencial, cristalizados na periferia das cidades seguindo períodos relevantes de expansão urbana (CONZEN, 2008). Observando a mancha urbana de Berlim, Lovis notou a formação de zonas heterogêneas (CONZEN, 2008), uma espécie de hiato no crescimento da cidade, responsáveis pelas descontinuidades na malha urbana (WHITEHAND; MORTON, 2004). Lovis classificou essas áreas como as urban fringe belts.

O conceito das urban fringe belts foi retomado em 1960 por M. R. G. Conzen que refinou e aprofundou os estudos sobre o tema (KRISTJANSDOTTIR, 2008). Conzen, inicialmente, aplicou a teoria de Louis à cidade de Alnwick, em 1960, e, posteriormente, à Newcastle, em 1962, incrementando a definição das urban fringe belts. Nos estudos de Newcastle, foram estabelecidas três fases do desenvolvimento das urban fringe belts: fixação, expansão e consolidação (CONZEN, 2008). O trabalho de M. R. G. Conzen apontou que as zonas que originam as urban fringe belts encontram-se temporariamente em posições periféricas e suas linhas de fixação são dadas por barreiras físicas, corpos hídricos, inclinação íngreme e barreiras antrópicas (KRISTJANSDOTTIR, 2008). Todavia, a principal contribuição do trabalho de M. R. G. Conzen foi demonstrar, pelo estudo dessas cidades britânicas tradicionais, que a paisagem urbana reflete sua história. Olhando para ela podemos identificar distintas fases de desenvolvimento e suas respectivas "regiões morfológicas", ou seja, diferentes conformações da ocupação urbana (WHITEHAND, 2009).

Posteriormente, em 1972, o geógrafo britânico Jeremy Whitehand deu sua contribuição ao conceito pela análise dos ciclos de edifícios institucionais e suas relações com períodos econômicos da vida urbana (CONZEN, 2008). Pereira Costa, Maciel, et al (2009) também verificaram que, mesmo aparecendo de modo descontínuo na malha urbana, as urban fringe belts são representantes dos ciclos do crescimento urbano.

Whitehand caracterizou as urban fringe belts por usos de solo heterogêneos predominantemente de caráter institucional de serviços públicos, tais como: educação, saúde, 
exército, pesquisa, recreação, cemitérios, ou até mesmo de usos religiosos ou atividades nocivas, em grandes lotes e com baixa densidade edificada (CONZEN, 2008).

Nesse sentido, as urban fringe belts podem se tornar barreiras ao crescimento urbano, uma vez que as cidades se expandem horizontalmente e essas áreas cristalizadas no tecido urbano - urban fringe belts estacionárias - formam limitações importantes. $\bigcirc$ crescimento da cidade tende a saltar essas áreas, formando os cinturões na malha urbana (KRISTJANSDOTTIR, 2008; WHITEHAND, 1988).

De modo geral, a partir do pressuposto que a malha urbana em contínua expansão tende a envolver as áreas estacionárias ${ }^{2}$, podemos dizer que as urban fringe belts acontecem em dois períodos: formação e posterior transformação. $\bigcirc$ período de formação é aquele no qual o crescimento da cidade está impulsionado e ocorre o salto da área já estabelecida, incluindo-a no tecido urbano. Antes que ocorra a transformação, a área sobrevive na paisagem da cidade, mesmo não estando mais em sua borda. Quando essas urban fringe belts acabam por se tornar mais centrais na mancha da cidade, a especulação imobiliária força a transformação da área devido ao valor da terra. Nesse período - transformação - os mais diversos novos usos podem ser dados a essas áreas, destacando-se a urbanização ou implantação de parques urbanos. Nesse contexto, vale ressaltar que hospitais e cemitérios têm um processo de mudança mais lento (KRISTJANSDOTTIR, 2008). Entretanto, Rego e Meneguetti (2011) reiteram que as urban fringe belts não se mesclam com os tecidos urbanos vizinhos, mas permanecem incongruentes.

\section{METODOLOGIA DE ESTUDO}

Antes de chegar-se a um método para a análise da malha urbana da cidade de Maringá, com o intuito de verificar a existência, a quantidade e a localização das urban fringe belts em uma cidade nova, é preciso considerar quais são as situações consideradas urban fringe belts para este trabalho.

Recapitulando, as urban fringe belts são grandes porções de baixa ocupação (até $40 \%^{3}$ ) e usos variados (usos públicos de acesso livre ou restrito). Por definição, são consideradas, neste trabalho, duas condições das urban fringe belts em Maringá: institucionais e privadas. As áreas institucionais podem ser: equipamentos educacionais, de saúde, militares, de pesquisa, de recreação, cemitérios, usos religiosos ou atividades nocivas. As áreas privadas podem ser: cemitérios, hospitais, clubes, universidades. Ainda em relação às áreas institucionais, considera-se como urban fringe belts as praças com tamanho mínimo equivalente a uma quadra, que tenham algum uso e não componham o sistema viário.

Além disso, são desconsideradas urban fringe belts quaisquer áreas que não se enquadrem no perfil descrito anteriormente. Do mesmo modo, os equipamentos institucionais planejados e inseridos na área do plano inicial de Maringá não são considerados urban fringe belts. Somente a zona industrial será considerada como urban fringe belt dentro do perímetro do plano inicial por causa da característica intrínseca à zona, além de sua extensão. De igual modo, as áreas de reservas florestais, por se 
tratarem de áreas protegidas por lei, englobadas na malha urbana, não serão consideradas urban fringe belts por não se transformarem, devido ao impedimento legal.

Assim como nos estudos de Kristjansdottir (2007), para promover a localização das urban fringe belts, neste estudo de caso, consideraram-se três barreiras. As barreiras físicas demonstram que as áreas de grande declividade, como fundos de vale, não são consideradas urban fringe belts. As barreiras sintéticas, por sua vez, eliminam a possibilidade de existência das urban fringe belts em porções cuja ocupação é proibida por lei. Já as barreiras econômicas auxiliam na localização e classificação das urban fringe belts conforme os ciclos de crescimento.

Além da contextualização histórica e econômica, o método a ser utilizado neste trabalho consiste na sobreposição e análise de mapas e sua persistência na evolução urbana, visando definir áreas que se encaixem no conceito ponderado anteriormente. Os mapas utilizados para o estudo foram: evolução urbana, equipamentos urbanos e praças, zoneamento urbano, sistemas de espaços livres e declividade média. Para complementar a análise, as urban fringe belts foram confirmadas por imagem de satélite.

Assim como na análise executada por Pereira Costa et al (2009), partindo da apreciação da imagem aérea da cidade e dos mapas de equipamentos e de espaços livres públicos, pôde-se encontrar áreas possíveis de serem definidas como urban fringe belts. Posteriormente, a análise junto do mapa de declividade média permite eliminar falsas possibilidades de existência de urban fringe belts, já que áreas com altas declividades não são favoráveis à ocupação.

Por meio da análise dos mapas de zoneamento urbano, foram averiguados usos heterogêneos do solo, e o mapa de sistema de espaços livres reafirmou que as áreas em questão são de baixa densidade de ocupação. Esses mapas foram fundamentais para a confirmação das urban fringe belts as quais, via de regra, são áreas de baixa ocupação que apresentam o entorno envolto pelo tecido urbano frequentemente apropriado com uso residencial.

mapa de evolução urbana auxiliou na averiguação das urban fringe belts devido à sua localização limítrofe entre a área urbana e a rural, no período de seu aparecimento. Embora algumas urban fringe belts sejam transformadas em áreas de acesso à população para algum uso - espaços livres ou de edifícios institucionais, muitas delas permanecem com sua característica original, de serem tão urbanas quanto rurais (WHITEHAND, 2001). A análise desse mapa permitiu ainda distinguir as épocas de formação dessas urban fringe belts.

Com o método, pretendeu-se detectar a existência das urban fringe belts, se elas têm permanecido, transformado-se ou, ainda, se desapareceram com as expansões urbanas. É preciso entender as urban fringe belts como um conjunto de lotes individuais que integram o desenvolvimento histórico e ecológico da cidade. Histórico, por representar o desenvolvimento da cidade por ciclos econômicos e ecológicos, pela característica de espaços livres que as urban fringe belts podem ter e assim compor o sistema de espaços livres na cidade (WHITEHAND; MORTON, 2003). Todavia, 
para se iniciarem as análises se faz necessário conhecer um pouco do histórico da cidade-estudo de caso.

\section{MARINGÁ - PARANÁ}

município de Maringá situa-se à latitude de $23^{\circ} 25^{\prime} 31^{\prime \prime} \mathrm{S}$ e longitude de $51^{\circ}$ 56' 19" W, no norte do estado do Paraná, sul do Brasil. A cidade, com 555 metros de altitude, está em uma região de clima subtropical com chuvas bem distribuídas ao longo do ano. Foi implantada sobre o divisor de águas das bacias hidrográficas dos rios Ivaí e Pirapó, e tem sua porção sul atravessada pela linha imaginária do Trópico de Capricórnio. Segundo o Censo do IBGE, em 2010 Maringá possuía 357.077 habitantes e, em sua unidade territorial de $488 \mathrm{~km}^{2}$, concentrava 734,15 hab./ $\mathrm{km}^{2}$. $\bigcirc$ grau de urbanização do município chegou a 97,76\% em 2010 (IBGE). Com sua economia baseada nos setores de comércio e serviços, a cidade abrange e emprega, desde os primórdios de sua fundação, pessoas das mais diversas etnias e culturas.

A cidade de Maringá, implantada em 1947, faz parte do esquema de colonização sistemática e urbanização deliberada em meio a um empreendimento de especulação fundiária iniciado por uma companhia britânica de especulação fundiária, por intermédio de sua subsidiária nacional, a Companhia de Terras Norte do Paraná - CTNP -, denominada a partir de 1951 de Companhia Melhoramentos Norte do Paraná - CMNP.

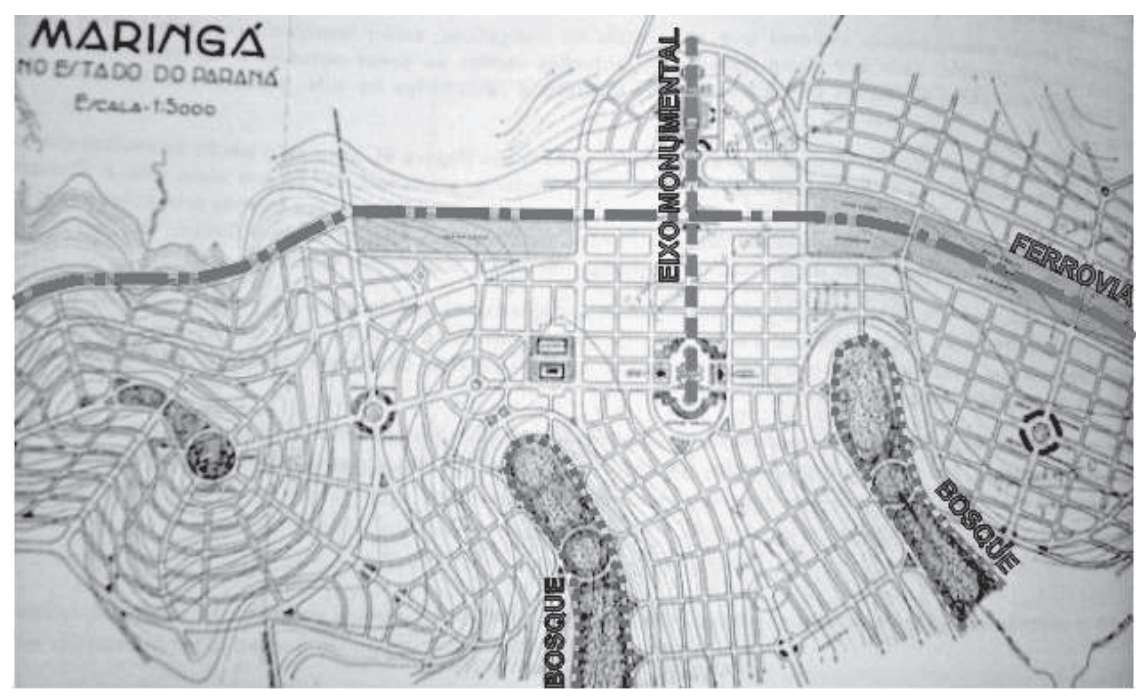

Figura: Anteprojeto de Maringá

Fonte: Meneguetti (2009) - adaptado

A concepção do conjunto da cidade está baseada na ferrovia que estruturou tanto a formação do conjunto das cidades quanto a ocupação do norte do Paraná, até então não urbanizado, a fim de propiciar o escoamento da produção agrícola dos lotes rurais que foram vendidos para impulsionar a colonização (Figura 1).

Otraçado da cidade demonstra a preocupação com a adaptação da forma urbana ao relevo tanto pelo aspecto central da estação ferroviária - porta de entrada da cidade e determinada a priori - quanto pela adaptação do desenho urbano às 
curvas de nível (Figura 1). O projeto original de Maringá foi elaborado pelo engenheiro urbanista Jorge de Macedo Vieira ${ }^{4}$, de acordo com os princípios formais da cidade jardim inglesa (REGO; MENEGUETTI, 2010). Assim ele foi condicionado ao sítio ao qual está se inserindo e, ao mesmo tempo, impõe-se ao organizar a cidade baseada em sua funcionalidade, criando áreas para os armazéns, bairros para operários, para classe média, o eixo monumental e o centro cívico, os bosques, enfim, determinando a hierarquia do meio.

\section{GÊNESE E EVOLUÇÃO DAS URBAN FRINGE BELTS EM MARINGÁ - PR}

As urban fringe belts identificadas em Maringá são áreas de baixa densidade e usos mistos, envoltas por loteamentos, em sua maioria, residenciais. Elas se constituem de áreas institucionais e/ou particulares. E, apesar de tratar-se de uma cidade nova, Maringá apresenta urban fringe belts que demarcam seus períodos de crescimento.

Na Figura 2, podemos observar o Plano Urbanístico Inicial da Cidade, em 1947, no qual consideramos como urban fringe belt somente o eixo ferroviário que atravessa a cidade e suas áreas industriais contíguas, e o pátio de manobras dos trens anexos a ele. Esse último, com o decorrer dos anos, consolidou-se como urban fringe belt por ser um elemento fundamental para o desenvolvimento inicial da cidade. $\bigcirc$ pátio de manobras corresponde à área das urban fringe belt mais modificada desde sua implantação, em decorrência do rebaixamento da ferrovia que propiciou o estabelecimento de novos usos para essas áreas. Vê-se, em sua extensão, desde campi universitários até elevados edifícios que compõem a porção mais central da cidade, denominada de Novo Centro.

Exceto essa área cuja classificação corresponde à zona industrial, não há mais urban fringe belts no perímetro inicial; os equipamentos institucionais incluídos no plano inicial da cidade eles não considerados urban fringe belts por terem sido orginalmente

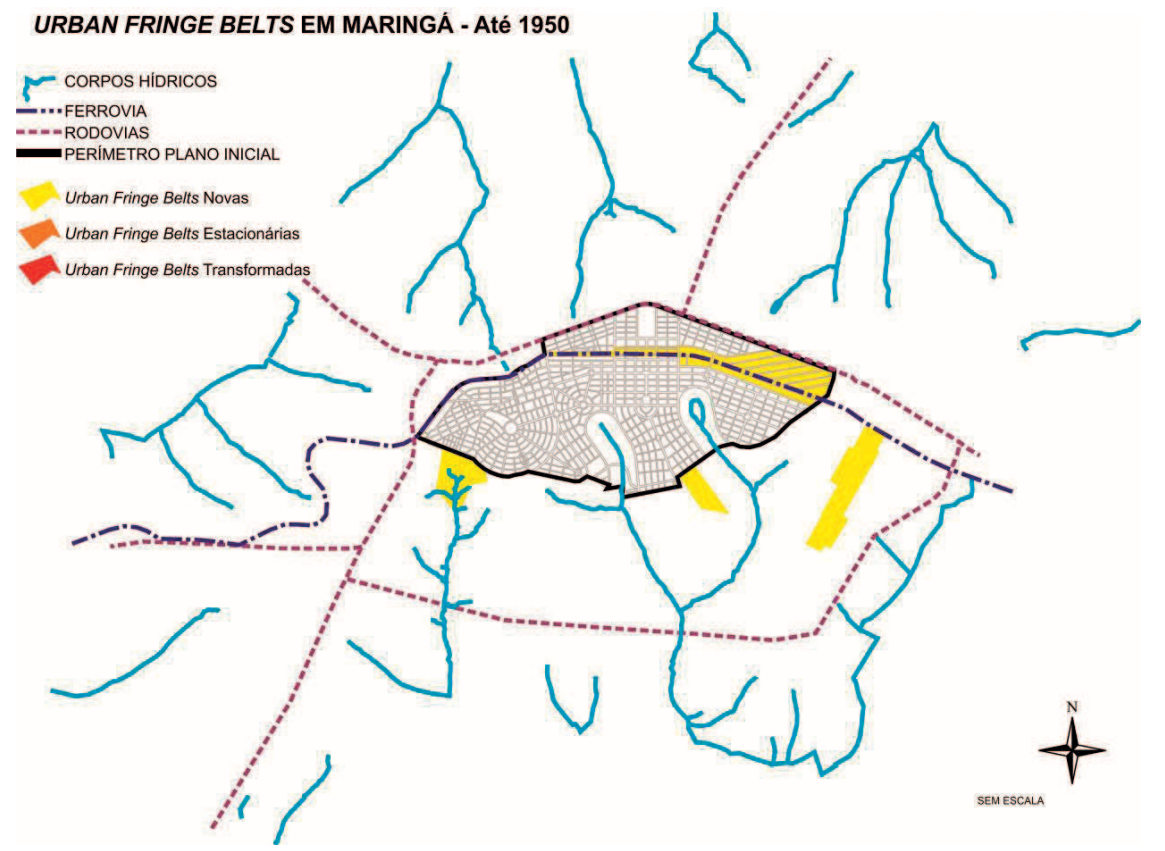

Figura 2: Urban fringe belts em Maringá, 1950 Fonte: Elaborado pelas autoras 
planejados. Mas, para além do perímetro, já se percebia a formação de outras três urban fringe belts: o Horto Florestal, o Cemitério Municipal e o Aeroporto. O Horto Florestal foi estabelecido com o intuito de fornecer mudas para a arborização urbana e preservar a terceira nascente junto da área central da cidade. O cemitério municipal passou a compor a porção central da cidade devido ao crescimento urbano. Já o aeroporto antigo, de baixa densidade, implantado em 1961, abriga hoje, em suas dependências, a Secretaria de Transportes - SETRAN. Nota-se, ainda, que as áreas dos três bosques do plano inicial não são consideradas urban fringe belts por serem planejadas desde o início para tal finalidade.

Ao se comparar a Figura 3, que demonstra o parcelamento inicial das chácaras que ladeiam a malha urbana, com a Figura 4, a proposta do Plano Diretor de 1967, percebemos que as urban fringe belts apresentadas anteriormente fazem parte do legado do projeto e ainda constatamos a influência das glebas rurais no desenho resultante da malha urbana no projeto das próximas décadas. Os novos loteamentos, limitados fisicamente pelas formas das chácaras, formaram-se descontínuos ao partido projetual do traçado original.

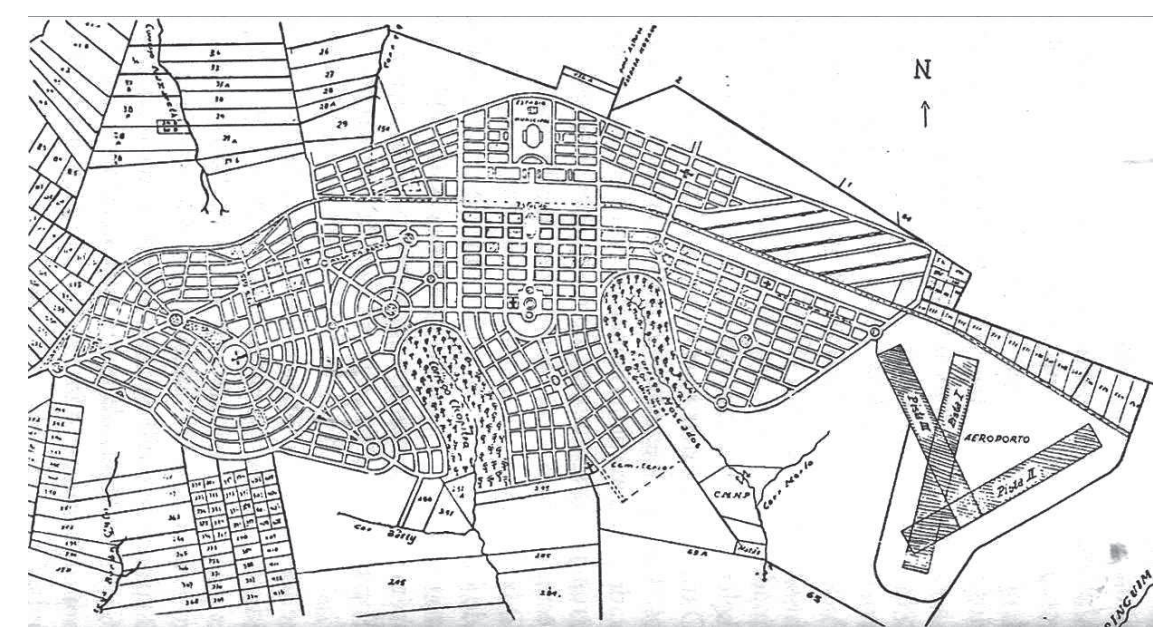

Figura 3: Projeto original de Maringá contendo parcelamento rural Fonte: Dias e Gonçalves, 1999

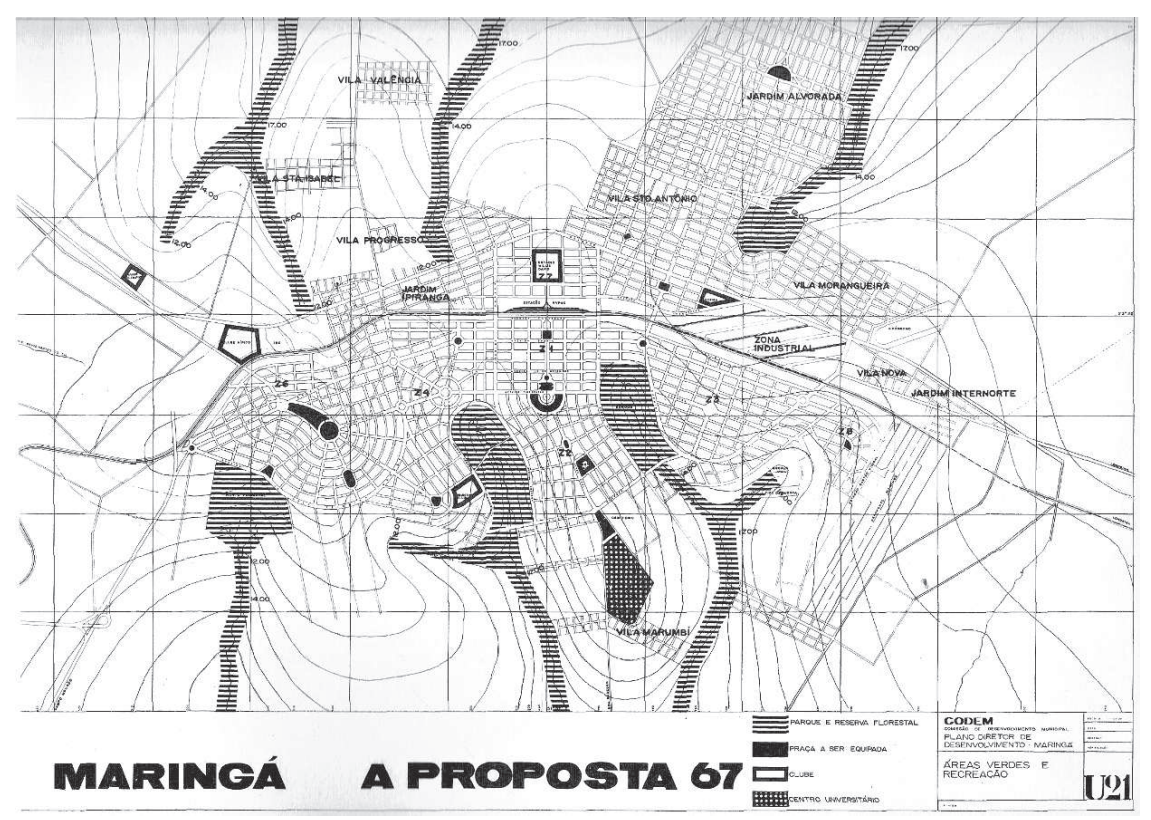

Figura 4: Planta proposta pelo Plano Diretor de 1967 Fonte: Meneguetti, 2009 
Nos anos 60, com a modernização da agricultura, a área urbana de Maringá se expandiu novamente. A porção a norte da ferrovia foi a primeira a sofrer expansão urbana. A implantação das novas vilas, observada na Figura 4, reafirma o ordenamento territorial ocasionado pela anterior delimitação das chácaras. Podemos considerar que essas foram as primeiras contribuições para a especulação imobiliária por provocar a implantação de infra-estrutura em vilas distantes da área em consolidação. A ausência de políticas de controle de expansão e de planejamento possibilitou essa situação.

Na Figura 5 nota-se que as urban fringe belts que estavam fora do perímetro inicial iá se encontram englobadas na malha urbana. Até 1965 podemos notar o aparecimento das urban fringe belts institucionais que surgiram para suprir a demanda habitacional. Ressalta-se também a inclusão de áreas correspondentes à nova zona industrial. Das urban fringe belts do período anterior, nenhuma sofreu alteração de seu uso, permanecendo estacionárias. Outro fator interessante é a criação de clubes de lazer ${ }^{5}$. Esses são incluídos nas bordas da área urbana e alguns deles continuam seus trabalhos no mesmo lugar. É importante ressaltar que, nessa época, previa-se em projeto a implantação do Centro Universitário próximo ao cemitério; todavia, isso não aconteceu.

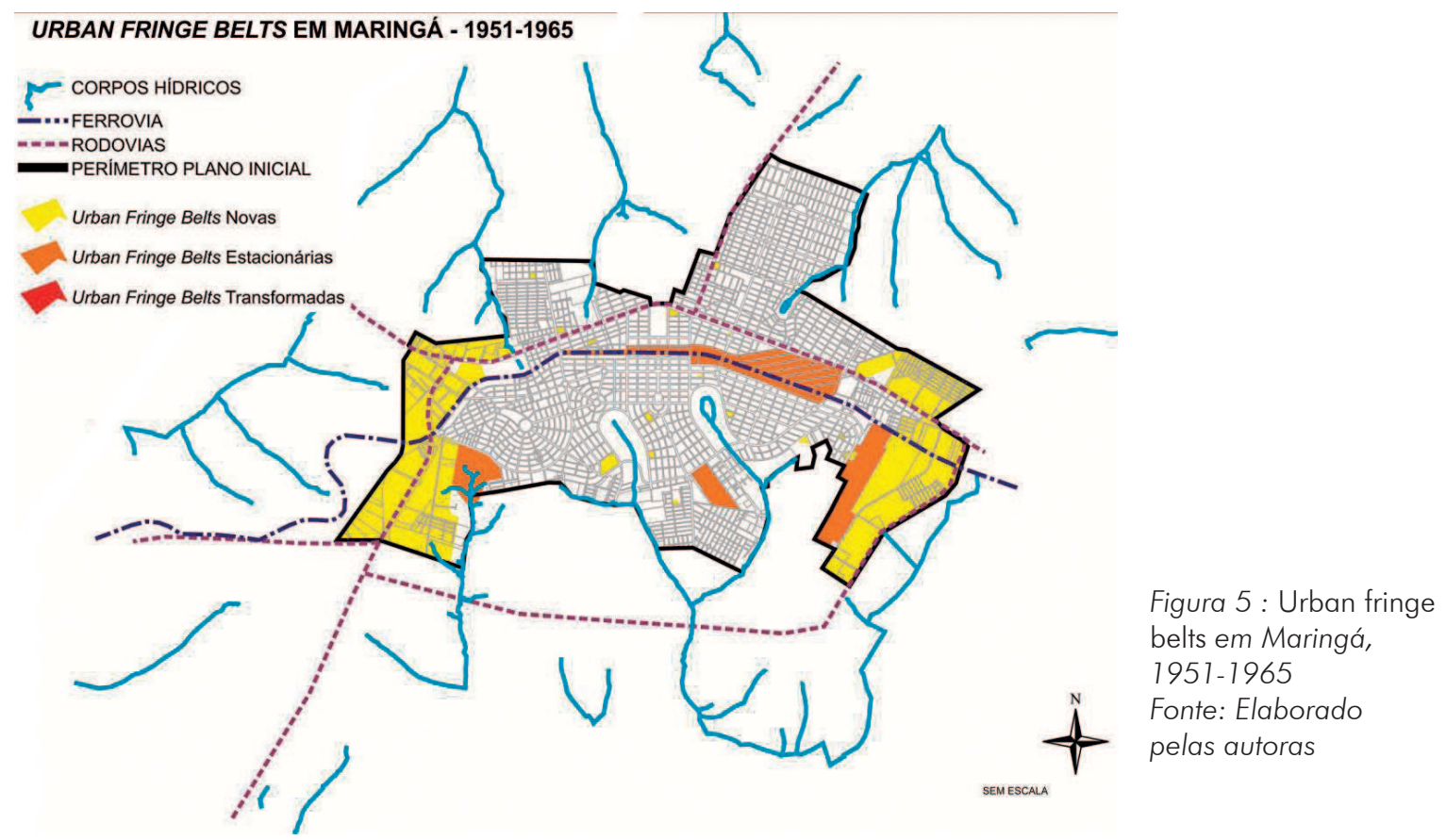

Outra característica a destacar-se é que a expansão urbana estava voltada para a região norte da cidade. Comparando as Figuras 3 e 4 podemos, mais uma vez, perceber o traçado do parcelamento das chácaras estabelecido anteriormente pelo primeiro projeto da cidade. Os novos bairros configuraram traçados distintos do restante do conceito do projeto original da cidade. Com a construção de bairros distantes da área urbana, em consolidação, faz-se necessária a implantação de novos equipamentos urbanos para a melhoria da qualidade de vida da população. $\bigcirc$ que confirma a definição das urban fringe belts de Kristiansdottir (2007) como sendo resultantes da necessidade de equipamentos urbanos em novos loteamentos. 
No fim dessa década, em 1968, foi aprovado o primeiro plano diretor. Percebe-se aí maior ocupação na porção norte da cidade. Nota-se, ainda, que foram estabelecidas áreas para expansão prioritária entremeio aos avanços da malha urbana para que se constituísse uma trama livre de vazios urbanos. As zonas industriais, que abrangiam porções a leste e a oeste da cidade, contribuíram para barrar o crescimento nessas direções. É importante considerar que o limite municipal de Maringá está próximo a essas áreas industriais. Com o decorrer do tempo, o crescimento urbano a leste e a oeste contribuiu para a conurbação com as cidades vizinhas Sarandi e Paiçandu, respectivamente.

Na década posterior, 1970, a zona rural continuou a perder população para a cidade. A modernização da agricultura, que promovia essa situação, ganhou uma aliada: a geada. A economia cafeeira na região ficou desestabilizada e a população afetada pela falta de trabalho no campo buscou a cidade como opção de campo de trabalho. Além dessas contribuições populacionais destaca-se o incremento decorrente da implantação da Universidade Estadual de Maringá. Ocupando primeiramente edificações escolares existentes, o campus definitivo da UEM iria se tornar tanto propulsor da expansão e adensamento urbanos ao norte da cidade quanto uma barreira física de grande amplitude.

Houve 69 novos loteamentos aprovados nessa época, expandindo o perímetro urbano da cidade, conforme a vontade dos empreendedores, sendo dotados ou não de infra-estrutura e equipamentos urbanos (MENEGUETTI, 2009). Essa situação contribuiu para que, em 1979, Maringá formulasse o Plano de Diretrizes Viárias para reger os futuros loteamentos, de forma a integrar os traçados que se constituíam de forma tão diversa.

Os espaços livres projetados em 1979, como o parque Alfredo Werner Nyfeller, já se encontravam envoltos por loteamentos urbanos, o que confere a eles o caráter das urban fringe belts planejadas. Todavia, as demais áreas de chácaras às margens de córregos não possuem a mesma classificação devido à impossibilidade de ocupação, como verificado em Belo Horizonte por Pereira Costa et al (2009).

No período de 1965 a 1980 (Figura 6) foi criada a zona industrial na porção oeste da cidade, formando uma grande urban fringe belt. Por outro lado, a área leste, anteriormente industrial, sofreu alteração de uso e deixou de ser urban fringe belt em sua maior parte. Além do acréscimo por zona industrial, podemos notar a presença de novos equipamentos institucionais como escolas, creches, praças recreativas, as companhias de água e luz, galpões do Instituto Brasileiro do Café - IBC, parque AIfredo Werner Nyfeller, lagoas de estabilização e a Universidade Estadual de Maringá. Também notamos outros usos, de baixa densidade, que caracterizam urban fringe belts em áreas periféricas da cidade. São eles: o Clube Social Acema e o Frigorífico Central (a sudeste, divisa municipal com Sarandi).

Onde se encontrava o antigo Hipódromo foi implantado o Parque de Exposições Francisco Feio Ribeiro, o qual representa a única urban fringe belt transformada no período. Apesar de ser uma área pública, a administração do mesmo foi delegada à 
Sociedade Rural de Maringá sob forma de comodato por um período de 20 anos. A área se encontra envolta por loteamentos de usos variados e possui baixa densidade. As demais urban fringe belts decorrentes do período anterior consolidaram-se e estagnaram-se.

Conforme o zoneamento aprovado em 1983, houve grande expansão das zonas residenciais, mas a zona industrial sofreu expansão predominante a sudoeste. Algumas áreas a leste, antes consideradas industriais, passaram a ser residenciais, contribuindo ainda mais para a conturbação entre os municípios de Maringá e Sarandi. Nesse sentido, a ocupação dos bairros ocorria, preferencialmente, a norte e nordeste, oposta à região industrial. Ainda na década de 1980 houve um período de estagnação na construção civil e na expansão da área urbana.

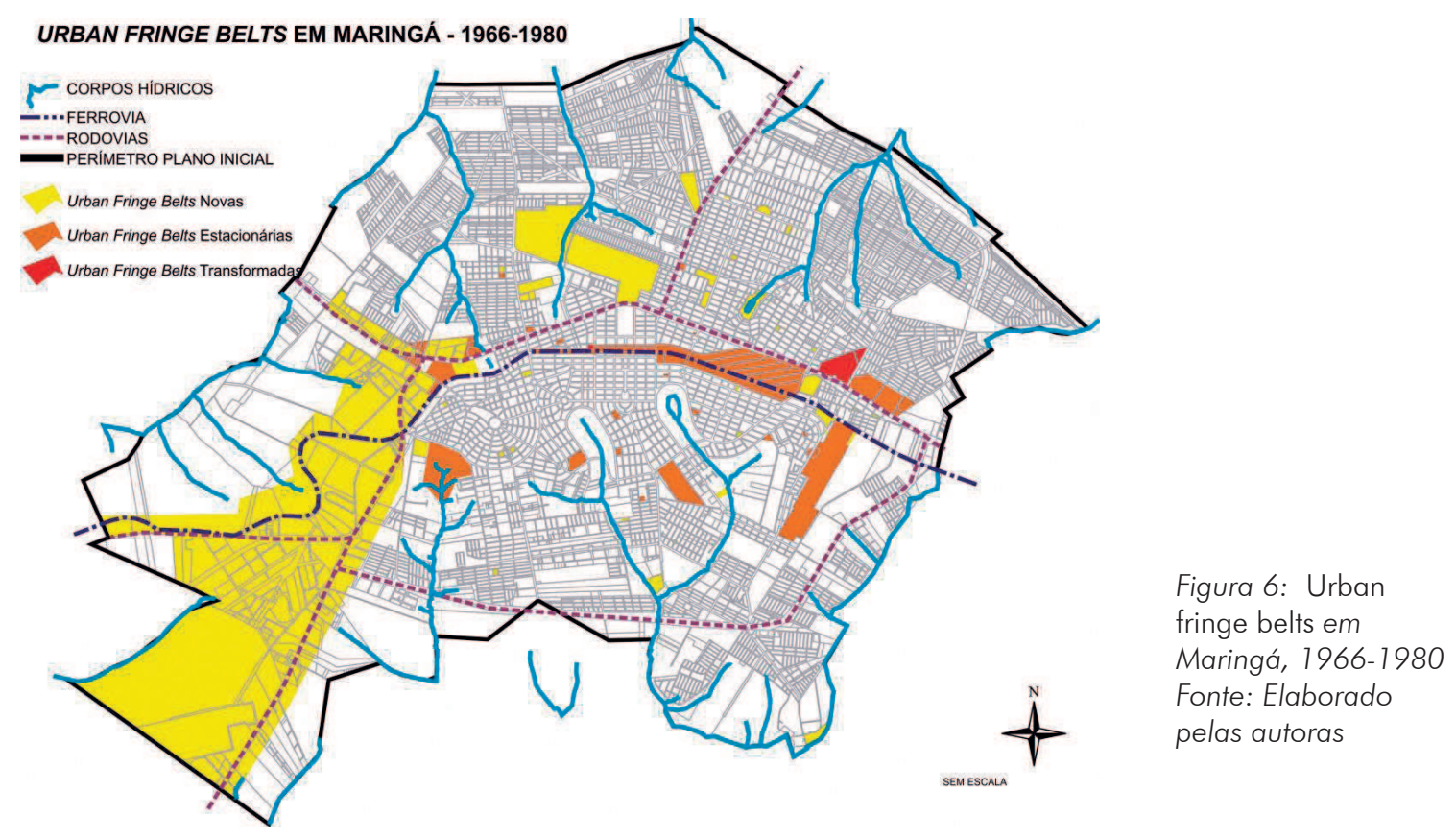

Apesar dos anos sombrios ocasionados pela queda de produção do café na década anterior, o expressivo êxodo rural acarretou o aumento populacional urbano e, com ele, Maringá, desenvolveu-se apostando em outras opções de economia. Resultado disso foram novos loteamentos e condomínios fechados implantados desde os anos 90 . 0 crescimento da cidade passou a ser expressivamente horizontal.

Nesse período, até 1995, muitos equipamentos públicos de educação são consolidados e construídos novos equipamentos nas regiões mais periféricas. $\bigcirc$ Cesumar (Centro Universitário de Maringá)/Colégio Objetivo, apesar de ser uma instituição privada, enquadra-se como urban fringe belt. $O$ zoneamento urbano foi responsável por grande porção das urban fringe belts em estagnação e por novas áreas de fringe belts próximas ao contorno sul. Nesse período não localizamos nenhuma urban fringe belt transformada, mas cabe ressaltar que outras urban fringe belts, consideradas periféricas no projeto inicial da cidade, são tidas em 2010 como centrais (Figura 7).

O zoneamento aprovado em 1991 pouco alterou as áreas estabelecidas pelo zoneamento anterior. Houve uma pequena expansão das zonas industriais. Nota-se, 


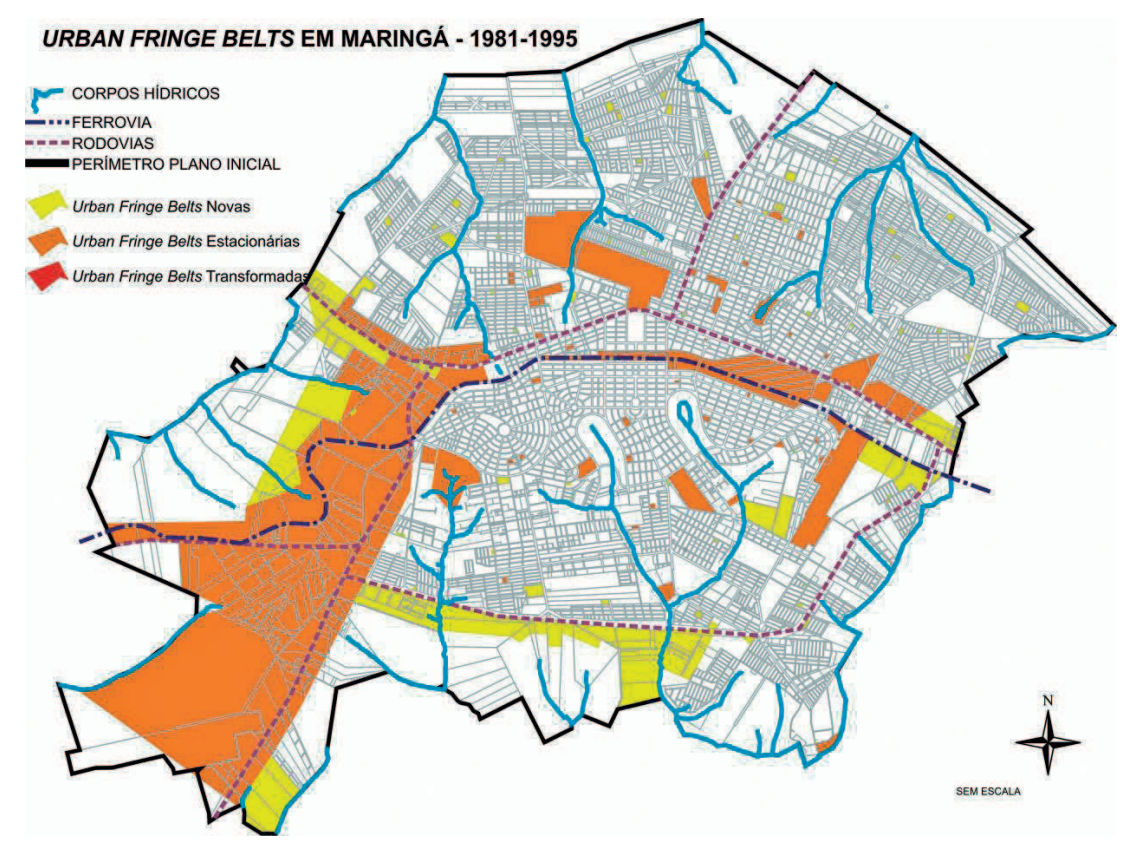

Figura 7: Urban fringe belts em Maringá, 1981-1995 Fonte: Elaborado pelas autoras

nesse instante, a ocupação de áreas próximas ao contorno sul, atenuando os vazios urbanos existentes, embora a ocupação residencial predominante continue nas zonas norte e nordeste.

Com o novo zoneamento, em 1999, os vazios urbanos existentes começaram a ser ocupados, principalmente no que se refere à porção norte, de maior expansão. Ao sul, embora haja ocupação dos vazios, ela é notavelmente inferior, se comparada à área norte. A expansão da zona industrial ocorreu, principalmente, no entorno do contorno sul. Não se nota loteamentos após as zonas industriais.

O Plano Diretor de Desenvolvimento de Maringá do ano 2000 visava coibir o parcelamento em zonas rurais para fins urbanos e propunha garantir que as áreas doadas à prefeitura fossem previamente elencadas para um uso específico que não poderia ser alterado, entre outros; todavia, esse Plano foi aprovado pela Câmara dos Vereadores em 2006 somente após inúmeras alterações (MENEGUETTI, 2009).

No último período em análise, até 2010 (Figura 8), aparecem novas urban fringe belts decorrentes do zoneamento urbano. Notamos também pequenas urban fringe belts institucionais, principalmente de equipamentos de educação. $O$ campus da Pontifícia Universidade Católica - PUC também aparece nesse período, com o Cemitério Parque. Esse, apesar de ter sido implantado em área de borda da cidade, já foi todo envolto por loteamentos urbanos de uso misto.

O Parque do Japão, ainda em construção, e o novo Aeroporto, nos limites do município, igualmente são novas urban fringe belts. Com a relocação do aeroporto, a antiga edificação passou a ser utilizada pela Secretaria Municipal de Transporte e a área de proteção do antigo aeroporto teve seu uso transformado, recebendo novos loteamentos de condomínios horizontais fechados.

O Clube Hípico e as antigas lagoas de estabilização também tiveram seu uso transformado. A urban fringe belt do clube recreativo, Clube Hípico, foi parcialmente 


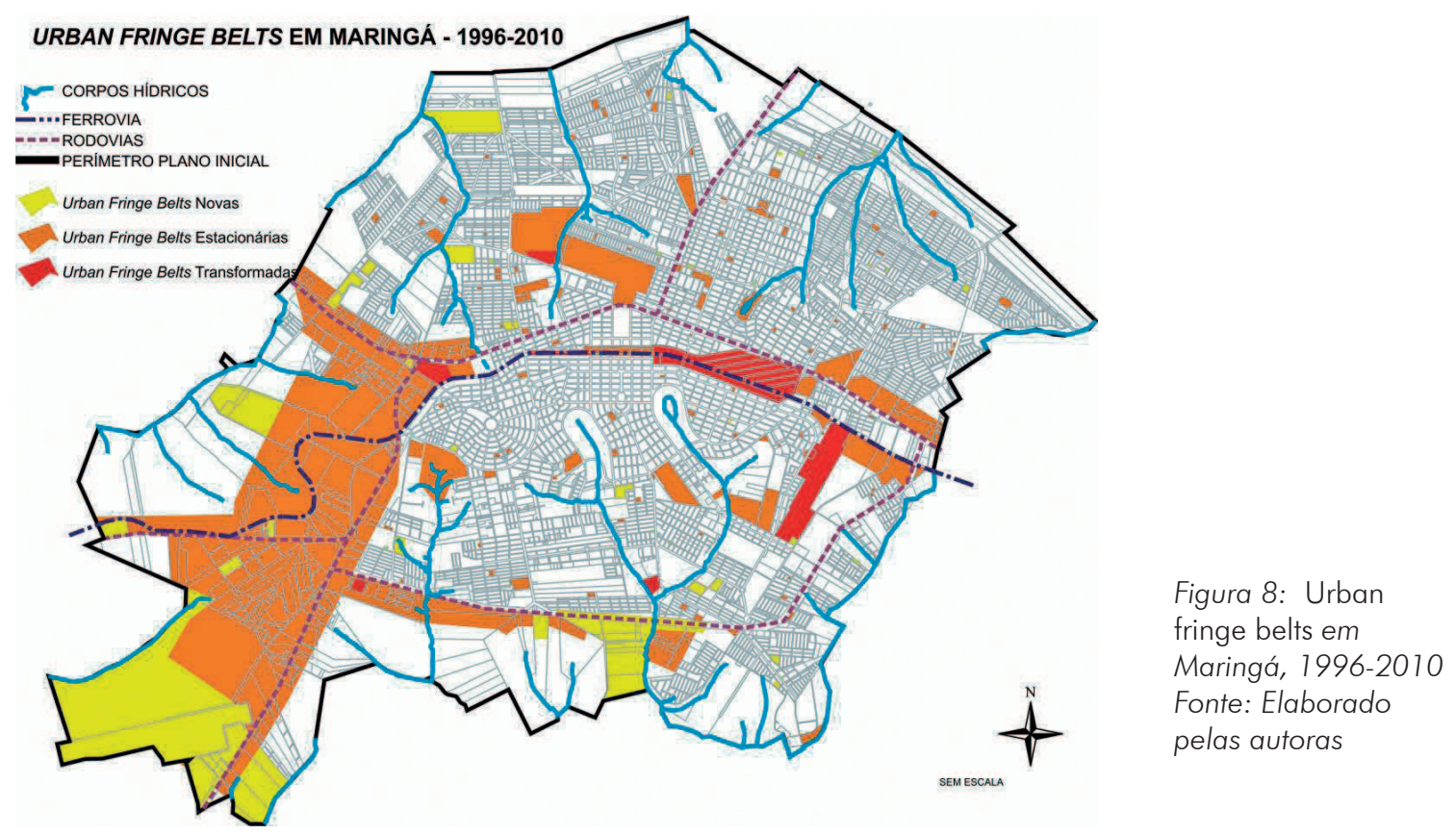

vendida para a construção de um shopping center de caráter regional - Shopping Catuaí. Essa mudança de uso impulsionará transformações futuras na estrutura urbana do entorno. Quanto à área das antigas lagoas de estabilização da Sanepar, está sendo construído o Parque do Trópico de Capricórnio, em parceria da prefeitura e investidores do Shopping Catuaí.

Ainda parte do terreno da UEM, ladeando a avenida Dr. Mário Clapier Urbinati, transformou-se em loteamento residencial. E, por fim, as áreas do pátio de manobras e linha férrea, na porção central da cidade, também estão sendo paulatinamente alteradas para usos mistos (residenciais, comerciais e de serviços).

Com as expansões imobiliárias e o loteamento em áreas de vazios urbanos, as urban fringe belts são contornadas. Embora a maioria das urban fringe belts estejam inseridas na malha urbana, percebemos a área do novo aeroporto como uma urban fringe belt a inserir-se nos próximos anos. Cabe ressaltar que em Maringá não existem urban fringe belts classificadas em decorrência da declividade, pois não há áreas com declividade superior a $50 \%$ que impediria a ocupação urbana. Toda a malha urbana encontra-se em declividades médias de, no máximo, 15\%.

\section{ANÁLISE DAS URBAN FRINGE BELTS}

Para a análise das urban fringe belts encontradas em Maringá, estabelecemos cinco períodos: 1947-1950 (Figura 2); 1951-1965 (Figura 5); 1966-1980 (Figura 6); 1981-1995 (Figura 7); 1996-2010 (Figura 8). Essa periodização se deu por conta das características dominantes de cada época. O primeiro período se refere, basicamente, à implantação do projeto original da cidade. O segundo período tem como característica as primeiras expansões urbanas, reguladas pelo primeiro Código de posturas e obras, de 1959. Sabemos que entre os dois primeiros períodos de análise, 1947-1967, 
a principal economia municipal estava baseada na venda das terras da companhia e início do povoamento, principalmente, dos lotes rurais. Todavia, foi no terceiro período de análise, 1967-1979, que ocorreu o auge da agricultura cafeeira a qual impulsionou o desenvolvimento econômico em diversas áreas. $\bigcirc$ marco de separação desse período é a aprovação do primeiro plano diretor (1967). Já nos dois últimos períodos, 1979. 2006, houve a transição da economia, passando do setor primário, de produção de matéria-prima, até se consolidar como setor terciário, de comercialização de produtos industrializados e prestação de serviços. Assim, o quarto período coincide com a grande verticalização da cidade, no centro e áreas adjacentes, e o quinto período com a expansão horizontal.

1o Período - até 1950 (Figura 2): as urban fringe belts são distantes uma das outras e têm tamanhos significativos na representação. São resultantes de usos periféricos de um plano inicial implantado integralmente. Ressalta-se, ainda, a proximidade delas ao eixo ferroviário, que atua como uma linha de fixação.

2 Período - 1951-1965 (Figura 5): as urban fringe belts do período anterior permaneceram estacionárias. As urban fringe belts das extremidades leste e oeste foram rodeadas por novas urban fringe belts originárias do zoneamento industrial e formam duas linhas de força no sentido norte-sul, nas porções oeste e leste da cidade. Elas podem ter representado uma barreira para o crescimento urbano, condicionando expansão da malha urbana ao sentido norte-sul devido às características das edificações e usos presentes nas porções leste e oeste do perímetro urbano. É valido ressaltar que essas novas áreas fazem limite ou compreendem parte de estradas rodoviárias e o eixo ferroviário. Esses elementos apareceram nos demais períodos também por se tratarem de linhas de fixação, úteis para a localização de algumas urban fringe belts. Percebemos ainda pequenas porções que representam os equipamentos institucionais estabelecidos na cidade para suprir a demanda criada pelo aumento populacional derivado dos novos loteamentos. Elas são menores e mais dispersas.

3을óodo - 1966-1980 (Figura 6): as urban fringe belts decorrentes do zoneamento industrial destacam-se e demarcam a parte leste como principal área de localização das urban fringe belts. Ainda nesse período aparecem outras urban fringe belts institucionais implantadas em diversas áreas da cidade, para que pudessem suprir as necessidades dos novos loteamentos. Embora pouco significativas em tamanho, essas pequenas urban fringe belts reafirmam a expansão urbana principal, a norte. As urban fringe belts que apareceram desde o início da cidade até 1965 continuaram estacionárias, com apenas uma exceção, que sofreu transformação, todavia, sem deixar de ser classificada como urban fringe belt. Assim, é de observar-se que as urban fringe belts dos dois primeiros períodos de análise, que correspondem a somente um período econômico, configuram-se e estabelecem-se no decorrer do ano como urban fringe belts internas, enquanto as urban fringe belts de 1965 a 1980 definem o que seriam as urban fringe belts intermediárias, se compararmos as definições de M. R. G. Conzen.

4- Período - 1981-1995 (Figura 7): as urban fringe belts de maior proporção em relação à escala da cidade ficaram rarefeitas na porção noroeste, a área de maior 
expansão residencial, acompanhando o crescimento residencial. Já as urban fringe belts decorrentes do zoneamento industrial se opõe ao crescimento urbano e ocorrem de forma contínua nas direções oeste e sul. Com o zoneamento da época concentrando as zonas industriais a sudoeste e estabelecendo zonas residenciais mais acessíveis financeiramente a nordeste, estabelece-se a prioridade de expansão. As demais urban fringe belts dos períodos anteriores permaneceram estacionárias sem sofrer qualquer alteração em seu uso.

5o Período - 1996-2010 (Figura 8): as urban fringe belts dadas por meio do zoneamento concentram-se nas direções oeste e sul. Observa-se urban fringe belts institucionais em bairros mais distantes da área urbana em consolidação. Porém, o maior destaque são as urban fringe belts estacionárias dos períodos anteriores e o início de processo de transformação das urban fringe belts centrais, em decorrência da especulação imobiliária. Com o quarto período retratam o momento da economia baseada nos setores de comércio e serviços. As urban fringe belts sugeridas então, juntas, compreendem o que seriam as urban fringe belts externas, conforme a conceituação de M. R. G. Conzen.

A evolução das urban fringe belts, conforme seus cinco períodos de análise, pode ser vista pela Figura 9. Ao focar a análise no tamanho das urban fringe belts, nota-se que há maior incidência delas na porção sudeste, leste e em parte do contorno sul, ambas devido ao zoneamento urbano industrial. Baseado nisso, pode-se afirmar que a maior expansão urbana foi contrária à zona das urban fringe belts industriais. Todavia, em relação às urban fringe belts pontuais nota-se que elas acompanham o crescimento da cidade, em decorrência dele.

Pela observação geral de todos os pontos das urban fringe belts, poder-se-ia afirmar o oposto: a maioria das urban fringe belts parecem acompanhar o crescimento da cidade,

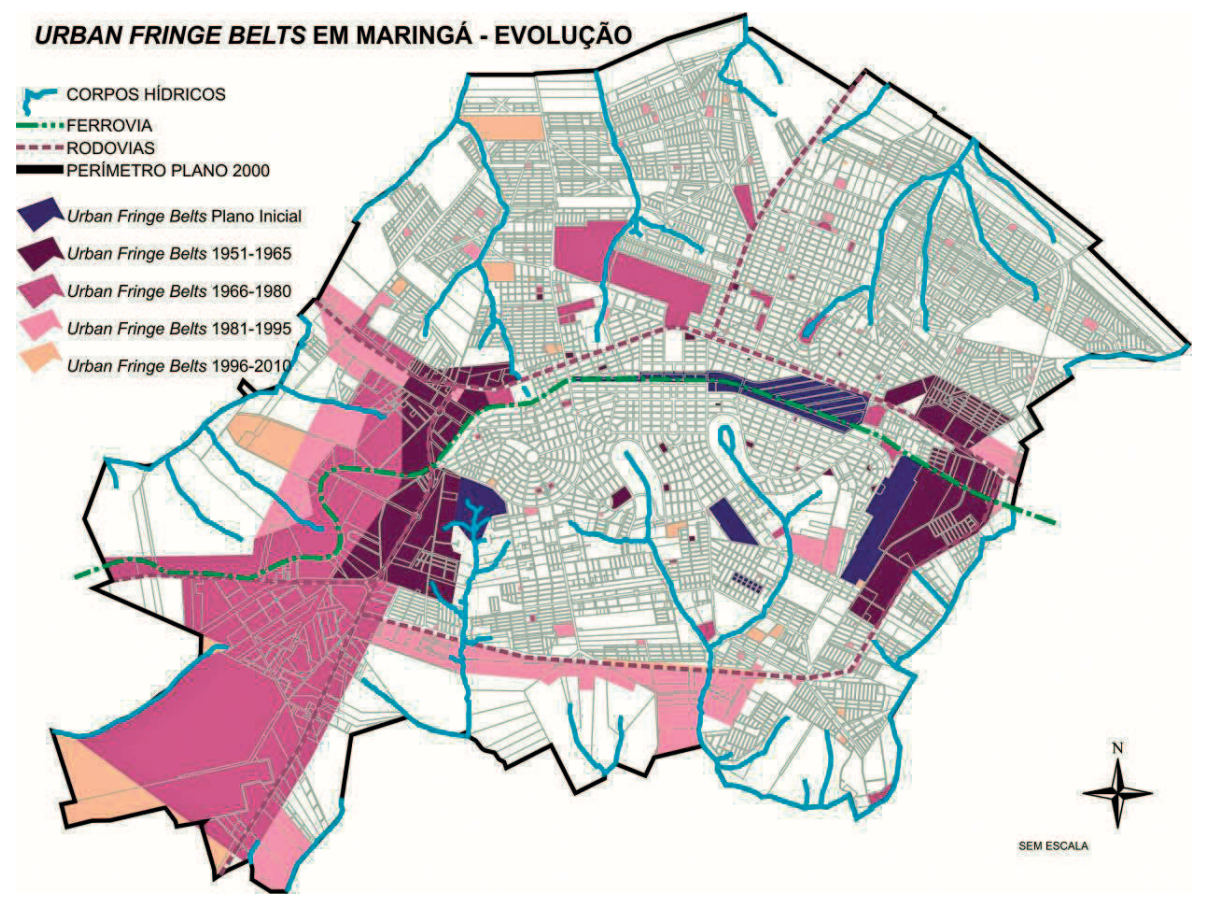

Figura 9: Evolução das urban fringe belts em Maringá

Fonte: Elaborado pelas autoras 
em decorrência dele. No entanto, analisadas as leis de zoneamento e conhecendo o contexto histórico de cada período de expansão, pode-se dizer que as duas afirmações são corretas por refletirem dois pontos de vista distintos.

Destaca-se, ainda, que as urban fringe belts industriais tendem a acompanhar linhas de fixação tais como rodovias e ferrovias. Em relação ao núcleo inicial central, percebe-se que as urban fringe belts urbanas circundaram-no de forma aleatória em todos os períodos de expansão; esses, por sua vez, são percebidos à medida que os equipamentos urbanos se distanciam da área central.

O que podemos acrescentar são as linhas de tendência de formação de cinturões das urban fringe belts (Figura 10) formadas pela indicação da atuação da urban fringe belts em relação à malha urbana próxima a ela. Nenhum período apresentou as urban fringe belts de modo que conformassem anéis. Ao observarmos as linhas de tendência de formação de todos os períodos, vemos que as urban fringe belts aparentam definir-se em cinturões de períodos complementares. Assim, podemos dizer que as urban fringe belts em cidades novas esboçam arcos que, embora não sejam concêntricos, vislumbram possíveis fragmentos de cinturões desconexos.

\section{CONCLUSÃO}

Apesar do contexto de uma cidade nova ser diferente do contexto originário das urban fringe belts, foi possível localizar as urban fringe belts em Maringá, seguindo os fatores descritos por Conzen. Mas nessas urban fringe belts observamos, além das similaridades com as urban fringe belts propostas pelo autor, particularidades de cidades novas e uma especificidade da cidade de Maringá.

\section{URBAN FRINGE BELTS EM MARINGÁ - Tendência de Formação}

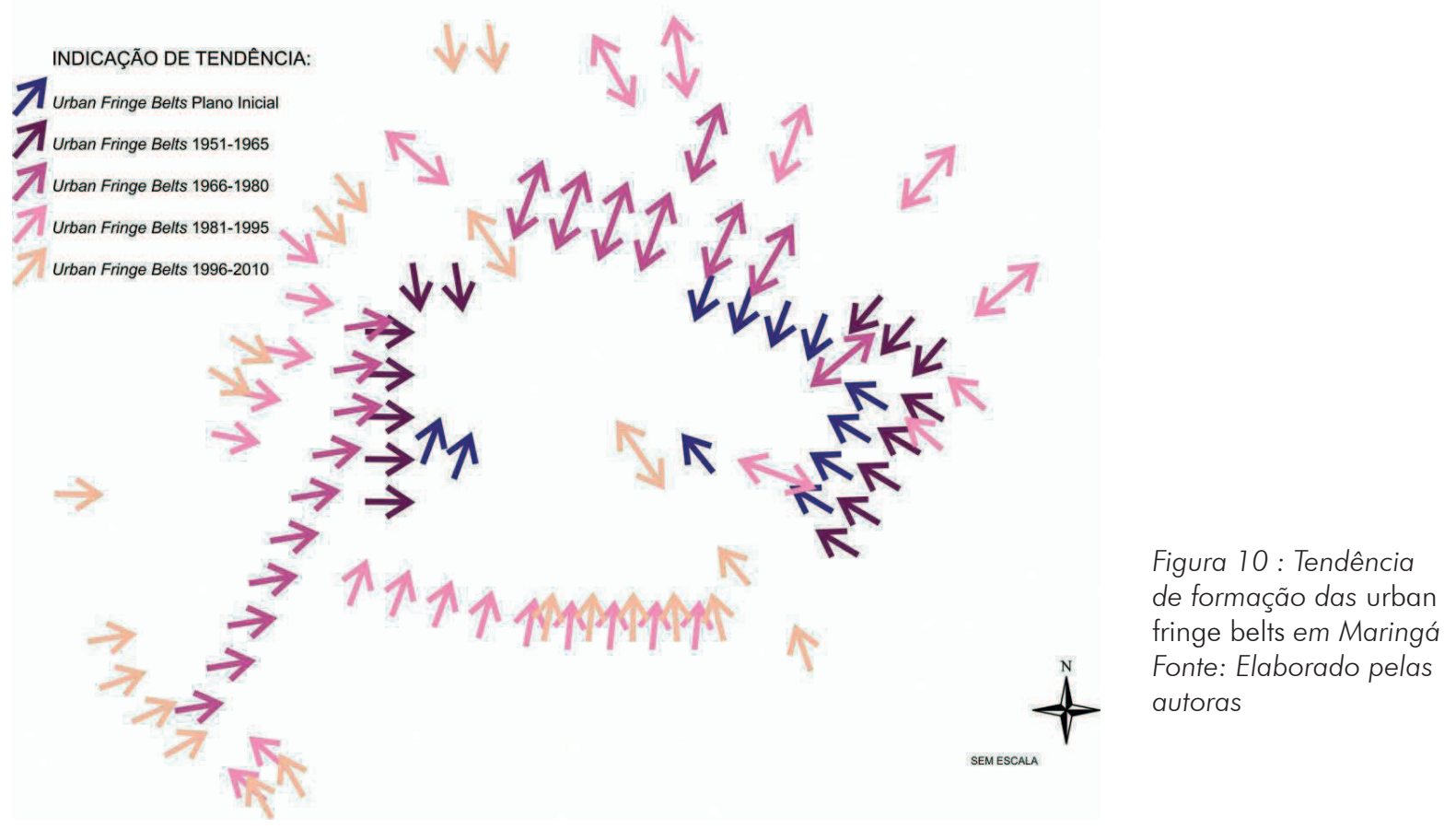


Em Maringá, as urban fringe belts não chegam a formar cinturões por serem localizadas de forma dispersa e fragmentada. Por conta do caráter planejado dessa cidade nova e de sua evolução (até certo ponto controlada e ordenada por leis), as urban fringe belts mais consistentes restringiram e condicionaram o crescimento urbano principal. Já as urban fringe belts menores não se davam em áreas de borda, e sim internamente ao loteamento urbano, de forma pontual, como resultantes das necessidades das áreas expandidas. Assim podemos agrupar as urban fringe belts de Maringá em dois grupos, de acordo com sua localização em relação às demais: urban fringe belts contínuas e urban fringe belts dispersas.

As urban fringe belts contínuas são de uso majoritariamente industrial e localizam-se, prioritariamente, em zonas de borda. Devido às implicações intrínsecas desse uso, seu entorno fica impróprio para uso residencial; assim, destaca-se que essas franjas são opostas à principal expansão das zonas residenciais. Já as urban fringe belts dispersas são planejadas e de uso institucional (equipamentos comunitários como escolas, creches e postos de saúde), acompanhando o crescimento urbano, conforme pede a Lei Federal n. 6.766/79 para novos loteamentos; ou de uso privado, ocorrendo de forma espontânea.

Também foi possível classificar as urban fringe belts tanto por sua evolução urbana quanto por sua dinâmica de transformação. Nota-se que grande parte das urban fringe belts que se modificam fazem-no por uma vez, permanecendo estacionárias posteriormente. Somente no último período de análise vemos um maior número das urban fringe belts em processo de transformação, caracterizando a lenta transformação das mesmas.

Apesar das urban fringe belts em Maringá não formarem cinturões, como observado por Conzen, é possível identificar as linhas de tendência de formação de arcos das urban fringe belts. Esses arcos que demonstram a tendência acabaram por circundar a porção central equivalente ao projeto inicial da cidade. Isso se deve ao projeto original ter sido implantado de uma só vez, gerando as primeiras urban fringe belts nas áreas periféricas da malha urbana inicial. As fringe belts posteriores cresceram em diferentes direções, em decorrência dos loteamentos que foram sendo implantados conforme a disponibilidade das chácaras urbanas do entorno. Todavia, a ocupação ocorreu de forma desordenada, implicando na consequente conformação das urban fringe belts.

Assim como observado por M. R. G. Conzen em Newcastle, percebe-se que a paisagem urbana de Maringá reflete sua história, seu desenvolvimento econômico e seu crescimento, de certa forma, ordenado. Identificaram-se três principais ciclos econômicos que se refletem nas urban fringe belts; são eles: 1947-1967 - compra e venda das terras da companhia; 1967-1979 - auge da agricultura cafeeira; 1979-2006 - economia voltada ao comercio e prestação de serviços. Esses ciclos podem ilustrar, por meio das linhas de tendência de formação das urban fringe belts, possíveis arcos que remetem às teorias de M. R. G. Conzen.

Sobretudo, cabe dizer que conhecer e determinar essas características da cidade possibilita intervir no tecido urbano de forma a propiciar melhorias, pelo reaproveitamento de áreas públicas para novas funções ou do controle da ocupação das mesmas, 
com o fim de manter a urban fringe belt inalterada. Da mesma forma, é possível prever novos usos para as áreas urbanas privadas para que, por exemplo, não se transforme as áreas de baixa densidade em alta densidade por meros fins especulativos, sem a manutenção da qualidade urbana herdada. Importa, principalmente, que nos subsidiemos a fim de intervir no espaço de forma responsável, para que possamos desfrutá-lo e conservá-lo e garantir que as futuras gerações tenham condições, de igual modo, de usufruí-lo.

\section{Notas}

(1) Optou-se por manter o termo em inglês porque a tradução simplória do mesmo poderia causar confusão com o conceito de franja urbana da geografia que consiste na zona de transição entre a cidade e o campo.

(2) Áreas que não sofreram transformações nem alterações seu uso.

(3) Foi considerada a faixa de estudo estabelecida pelo núcleo local do Quadro de Paisagismo no Brasil - Sistemas de Espaços Livres (QUAPÁ-SEL), conforme a realidade da cidade de Maringá.

(4) Engenheiro paulista (1894-1978) formado pela Escola Politécnica da USP, Vieira trabalhou com Barry Parker, urbanista inglês, na Companhia City no início do século passado.

(5) Clube Olímpico, Clube Hípico, Country Club e Hipódromo.

\section{Bibliografia}

CONZEN, M. P. How growing cities internalize their old urban fringes: A cross-cultural comparison. In: INTERNATIONAL SEMINAR ON URBAN FORM, 2008, Artimino. Anais... Artimino - Itália: ISUF, p. 21 -23, 2008.

DIAS, R. B.; GONÇALVES, J. H. R. (Org.). Maringá e o norte do Paraná. Maringá: Eduem, 1999.

KRISTJANSDOTTIR, S. Fringe belts and green belts: "the relationship between former fringe belts and todays greenbelts" - a case study from Reykjavík, Iceland, In: INTERNATIONAL SEMINAR ON URBAN FORM, 2008, Artimono. Anais... Artimino, Itália: ISUF, 2008.

KRISTJANSDOTTIR, S. Fringe belts: you know when you are in them. INTERNATIONAL SEMINAR ON URBAN FORM, 2007, Ouro Preto. Anais... Ouro Preto: ISUF, 2007.

MENEGUETTI, Karin Schwabe. Cidade jardim, cidade sustentável: a estrutura ecológica urbana e a cidade de Maringá. Maringá: Eduem, 2009.

PEREIRA COSTA, S. de A. et al. Fringe belts no município de Belo Horizonte. In: TÂNGARI, V. R.; ANDRADE, R.; SCHLEE M. B. (Org.). Sistema de espaços livres - o cotidiano, apropriações e ausências. Rio de Janeiro: Universidade Federal do Rio de Janeiro, v. único, 2009.

REGO R. L.; MENEGUETTI, K. S. A respeito de morfologia urbana. Tópicos básicos para estudos da forma da cidade. Acta. Scientiarum. Technology, Maringá: Editora da Universidade Estadual de Maringá, v. 33, n. 2, p. 123-127, 2011.

REGO, R. L.; MENEGUETTI, K. S. Planted towns and territorial organization: the morphology of a settlement process in Brazil. Urban Morphology, Alemanha, v. 14, n. 2, p. 101-109, 2010.

WHITEHAND, J. W. R. British urban morphology: the conzenian tradition. Urban Morphology, EUA, v. 5, n. 2, p. 103$109,2001$.

WHITEHAND, J. W. R. The structure of urban landscapes: strengthening research and practice. Urban Morphology, China, v. 13, n. 1, p. 5-27, 2009.

WHITEHAND, J. W. R.; MORTON N. J. Fringe belts and the recycling of urban land: an academic concept and planning practice. Environment \& Planning B: Planning \& Design, Inglaterra, v. 30, n. 6, p. 819-839, 2003.

WHITEHAND, J. W. R.; MORTON N. J. Urban morphology and planning: the case of fringe belts. Cities, Canadá: Elsevier, v. 21, n. 4, p. 275-289, 2004. 